\title{
Systemic and local levels of fetuin-A in calcific aortic valve stenosis
}

\author{
JENS J. KADEN ${ }^{1 *}$, JOCHEN O. REINÖHL ${ }^{1 *}$, BIRGIT BLESCH $^{1}$, MARTINA BRUECKMANN $^{1}$, \\ DARIUSCH HAGHI ${ }^{1}$, MARTIN BORGGREFE ${ }^{1}$, FABIAN SCHMITZ ${ }^{2}$, \\ SEBASTIAN KLOMFASS ${ }^{2}$, MANUELA PILLICH ${ }^{2}$ and JAN R. ORTLEPP ${ }^{2,3}$
}

${ }^{1}$ First Department of Medicine, Medical Faculty Mannheim, University of Heidelberg, Mannheim; ${ }^{2}$ Medical Clinic I,
University Hospital Aachen; ${ }^{3}$ Clinic for Internal Medicine and Intensive Care, Asklepios Hospital, Seesen, Germany

Received February 28, 2007; Accepted April 4, 2007

\begin{abstract}
Calcific aortic valve stenosis, the most frequent heart valve disorder in developed countries, is an actively regulated process with similarities to bone formation. Fetuin-A has recently been identified as a potent circulating inhibitor of calcification. While several studies involving patients with end-stage renal disease have shown an association between low serum fetuin-A and cardiovascular calcification, nothing is known about fetuin-A serum levels in non-renal patients with calcific aortic valve stenosis. Furthermore, while fetuin-A has been localized in calcified areas of atherosclerotic arteries, data about fetuin-A deposition in stenotic aortic valves are unavailable at present. Serum fetuin-A levels were determined in patients with $(n=31)$ and without $(n=28)$ calcified aortic valve stenosis by ELISA. Creatinine and CRP levels were determined and glomerular filtration rate (GFR) was calculated by the MDRD formula. Immunohistochemistry for fetuin-A was performed on human calcified stenotic $(n=14)$ and control $(n=8)$ aortic valves using a monoclonal antibody. Serum fetuin-A levels were lower in patients with calcific aortic stenosis as compared to the control group $(1.41 \pm 0.33$ versus $1.57 \pm 0,27 \mathrm{mg} / \mathrm{dl} ; \mathrm{p}=0.046)$. This difference was particularly evident in individuals with a normal GFR $\geq 60 \mathrm{ml} / \mathrm{min}$ $(1.36 \pm 0.24$ versus $1.63 \pm 0.27 \mathrm{mg} / \mathrm{dl} ; \mathrm{p}=0.007)$. Furthermore, specific staining of fetuin-A was found in stenotic valves but not in healthy control valves. The data suggest a role of fetuin-A in the pathogenesis calcific aortic valve stenosis independently of the renal function and support the concept that mechanisms of calcium homeostasis are involved in the development of calcific aortic stenosis.
\end{abstract}

Correspondence to: Dr Jens J. Kaden, Universitätsklinikum Mannheim, I. Medizinische Klinik, Theodor-Kutzer-Ufer 1-3, D-68167 Mannheim, Germany

E-mail: jens.kaden@med.ma.uni-heidelberg.de

${ }^{*}$ Contributed equally

Key words: aortic stenosis, fetuin-A, valvular calcification, calcium homeostasis

\section{Introduction}

Calcific aortic valve stenosis is the most common heart valve disorder in developed countries and the main cause of heart valve replacement in the elderly. It is associated with inflammatory cell infiltration, increased cellularity and an accumulation of pro-inflammatory molecules such as tumor necrosis factor (TNF)- $\alpha$ (1). Although calcific aortic stenosis was considered a passive precipitation of calcium in the valve, subsequent findings rather suggest an actively regulated process of bio-mineralization that shares morphological similarity with bone formation (2). Accordingly, various groups have demonstrated an expression of bone-associated proteins, including bone sialoprotein, osteopontin, osteonectin, osteocalcin and tenascin C $(2,3)$.

Fetuin-A is a circulating serum protein with a molecular weight of $58 \mathrm{kDa}$. It was first described as the major globulin in fetal and newborn calf serum. As a member of the cystatin superfamily of cysteine protease inhibitors, it is synthesized by hepatocytes and reaches high serum concentrations (4). Fetuin-A is a negative acute-phase protein that is downregulated after infection or trauma. It is ubiquitously present in the extracellular space and has been identified as a potent circulating inhibitor of the calcification process (5). Fetuin-A perturbs hydroxyapatite formation by reducing crystal formation (6). It also can assemble a high molecular mass complex with calcium phosphate mineral and matrix $\gamma$ carboxyglutamic acid protein (MGP), a key regulator of tissue calcification (7). Furthermore, it has been shown to antagonize osteogenic growth and differentiation factors, to control bone metabolism, to play a basic role in phagocytosis regulation and, finally, to mediate vascular smooth muscle cell (VSMC) calcification (8-10). In a transgenic mouse model, ablation of the fetuin-A gene resulted in progressive fatal calcification of soft tissues such as kidney, skin, lungs, vasculature, myocardium and heart valves (5).

Patients with end-stage renal disease (ESRD), in whom cardiovascular calcification is common, often have low serum concentrations of fetuin-A, and the serum from these patients showed a reduced capacity to inhibit calcification in vitro $(5,11)$. Fetuin A levels were inversely associated with the amount of coronary artery calcification as assessed 
Table I. Clinical data of patients in whom serum fetuin-A was analyzed.

AS (n=31) Controls $(n=28)$ p-value

\begin{tabular}{lccr}
\hline Age (years) & $72 \pm 7$ & $69 \pm 5$ & 0.070 \\
Male gender & $14(45 \%)$ & $15(54 \%)$ & 0.606 \\
Diabetes mellitus & $8(26 \%)$ & $6(21 \%)$ & 0.766 \\
Arterial hypertension & $23(74 \%)$ & $22(79 \%)$ & 0.766 \\
Smoking & $13(42 \%)$ & $12(43 \%)$ & 1.000 \\
Creatinin & $1.17 \pm 0.31$ & $1.09 \pm 0.18$ & 0.226 \\
GFR $(\mathrm{ml} / \mathrm{min})$ & $56 \pm 16$ & $60 \pm 10$ & 0.278 \\
CRP & $14 \pm 27$ & $7 \pm 6$ & 0.258 \\
Hypercholesterolemia & $11(36 \%)$ & $23(82 \%)$ & $<0.001$ \\
Stenotic coronary & $11(36 \%)$ & $23(82 \%)$ & $<0.001$ \\
artery disease & & & \\
\hline
\end{tabular}

AS, calcific aortic stenosis; GFR, glomerular filtration rate; CRP, C-reactive protein. ${ }^{a}$ No patient suffered end-stage renal disease (highest creatinine was $2.1 \mathrm{~g} / \mathrm{dl}$ ).

by computed tomography (12). The role of fetuin-A during the pathogenesis of calcific aortic stenosis, however, is currently unknown. Based on the hypothesis that an association between low serum fetuin-A levels and valvular calcification may also exist in patients with calcific aortic stenosis, the present study evaluated the serum levels of fetuin-A in patients with degenerative aortic stenosis and in controls. Furthermore, the accumulation of fetuin- $\mathrm{A}$ in human aortic valves with and without calcific aortic stenosis was determined.

\section{Materials and methods}

Serum samples and enzyme-linked immunosorbent assay (ELISA). Venous blood samples were taken from 31 patients with severe calcific aortic stenosis before coronary angiography. As controls, samples were taken from 28 patients undergoing left heart catheterization for suspected coronary artery disease. In all controls, calcification on fluoroscopy of the aortic valve was absent, valve separation was normal and no gradient $>5 \mathrm{mmHg}$ across the valve was present during catheter pullback. There were no patients with ESRD in any of the groups. Hypercholesterolemia was considered present if the total fasting serum cholesterol was $>200 \mathrm{mg} / \mathrm{dl}$ or if the patient was taking cholesterol-lowering medication. Arterial hypertension was considered present if the resting blood pressure was $>140 / 90 \mathrm{mmHg}$ or if the patient was taking antihypertensive medication. Diabetes mellitus was considered present if the fasting serum glucose concentration was $>126 \mathrm{mg} / \mathrm{dl}$ or if the patient was taking antidiabetic medication. Coronary artery disease was considered present if at least one stenosis $>50 \%$ was demonstrated during coronary angiography. Creatinine, glomerular filtration rate (GFR) as assessed by the MDRD formula, and serum $C$ reactive protein (CRP) were measured. In cases in which the CRP value was below the detection limit of $5 \mathrm{mg} / \mathrm{l}$ the value of $5 \mathrm{mg} / \mathrm{l}$ was used for further calculations. Fetuin-A serum concentrations

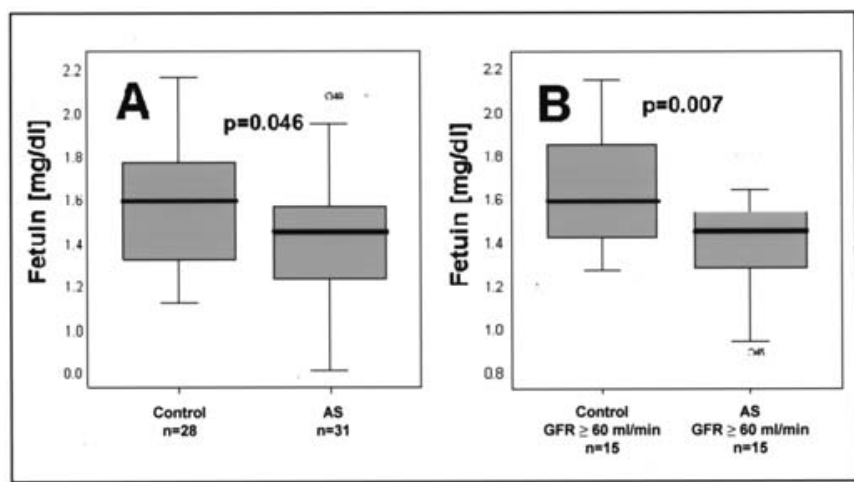

Figure 1. Serum fetuin-A levels. A, significantly lower serum levels of fetuin-A in patients with calcific aortic stenosis as compared to the control group. B, subgroup analysis of patients with a normal GFR $\geq 60 \mathrm{ml} / \mathrm{min}$, yielding a highly significant difference in fetuin-A levels between patients with calcific aortic stenosis and controls.

were analyzed using a commercially available colorimetric ELISA kit standardized with human recombinant fetuin-A (generous gift of Biovendor GmbH, Heidelberg, Germany). All samples were assessed in duplicate.

Aortic valve tissue and immunohistochemistry. Human tricuspid calcified aortic valves were obtained from 14 patients undergoing valve replacement for clinical calcific aortic stenosis As controls, 8 aortic valves were obtained at autopsy from patients without clinical and morphological aortic stenosis. Valve leaflets were rinsed in cold saline, fixed in $4 \%$ buffered formalin, and embedded in paraffin. Single-label immunohistochemistry was performed using the avidin-biotin complex method (Vector Laboratories, Burlingame, USA) as described previously (13). After removal of paraffin and hydration sections were boiled in citrate buffer for antigen retrieval, and endogenous peroxidase activity was blocked with methanolic hydrogen peroxide. Sections were washed with phosphatebuffered saline and incubated with anti-fetuin-A primary antibody. After washing, a biotin-labeled horse anti-mouse antibody was applied, followed by an avidin-biotin-peroxidase conjugate for $30 \mathrm{~min}$. As chromogen, 3-amino-9-ethylcarbazole was used yielding a brick-red reaction product. Cell nuclei were counterstained with Meyer's hematoxylin. Liver tissue served as positive control whereas the primary antibody was omitted for negative controls.

Statistical analysis. For statistical analysis, the commercially available software SPSS (Version 12.0, SPSS, Chicago, USA) was used. Continuous data are presented as mean \pm SD and categorical data are presented as frequencies. For continuous variables ANOVA was used. For comparisons of categorical variables, chi-square analysis was performed. A probability value $<0.05$ was considered statistically significant.

\section{Results}

The characteristics of the study population are summarized in Table I. Serum fetuin-A levels of patients with calcific aortic stenosis were significantly lower as compared to those of the control group (Fig. 1A). This was particularly evident in the 


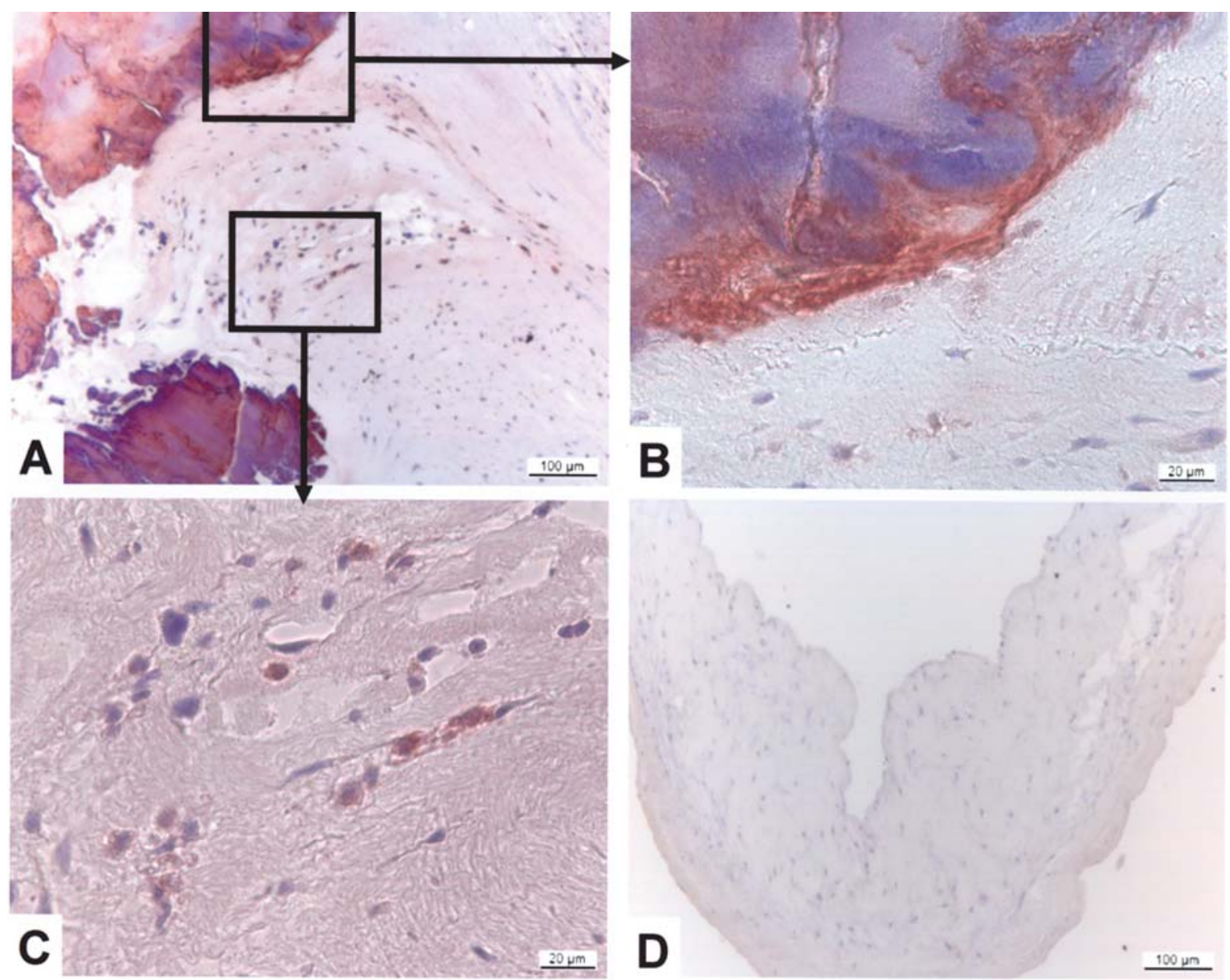

Figure 2. Immunohistochemistry for fetuin-A. A-C, stenotic valve. Specific staining of fetuin-A in association with areas of focal calcification. B, high-power magnification of boxed area in A, showing fetuin-A staining around and within the calcifications. C, high-power magnification of boxed area in A, showing fetuin-A staining of cells surrounding the calcifications. D, control valve without specific staining.

subgroup of patients with a normal GFR $\geq 60 \mathrm{ml} / \mathrm{min}$ (Fig. 1B). In immunohistochemistry, specific staining of fetuin-A was found in stenotic valves in association with areas showing morphological features of focal calcific deposits (22) (Fig. 2AC). Fetuin-A staining was detectable within the calcifications (Fig. 2B) and in cells surrounding the calcifications (Fig. 2C). No staining was detected in normal valves (Fig. 2D).

\section{Discussion}

Our data show that serum fetuin-A levels are decreased in patients with calcific aortic valve stenosis as compared to a control group without aortic stenosis. Previous studies identified fetuin-A as a potent circulating inhibitor of calcification (5). Ablation of the mouse fetuin-A gene in a strain of calcificationprone mice results in progressive fatal calcification of soft tissues, including kidney, testis, skin, heart, and vasculature (5). Conforming to our data, Fetuin-A deficient mice also showed significant valvular calcification in this model (5). Reduced fetuin-A levels, combined with lowered levels of MGP and an abundance of pro-calcific factors such as hypercalcemia, hyperphosphatemia and dyslipidaemia, are thought to disturb the balance of pro-calcific versus calcification-protecting factors in ESRD patients. Therefore, patients undergoing hemodialysis or peritoneal dialysis almost always show extensive cardiovascular calcification $(11,14,15)$. In ESRD patients, fetuin-A deficiency is associated with malnutrition, inflammation and cardiovascular calcification as well as with an increased all-cause and cardiovascular mortality $(14,15)$. The association between low fetuin-A levels and the presence of cardiovascular calcification proved to be independent of established cardiovascular risk factors (14). Fetuin-A can exert its effects by various mechanisms of action. In contrast to other inhibitors of ectopic calcification such as MGP, fetuin-A acts in all extracellular fluids and is not locally restricted. Most notably, it perturbs hydroxyapatite formation, reduces crystal formation, and regulates energy and bone metabolism $(6,9,16)$. Fetuin-A inhibits the calcification-inducing effects of transforming growth factor $B$ and bone morphogenetic protein- 2 which both have been shown to promote valvular calcification (17-20). Moreover, fetuin-A may suppress the release of TNF $\alpha$, a potent regulator of valvular and vascular calcification (21-24).

Apart from demonstrating lowered fetuin-A serum concentrations in patients with calcific AS, our results show that fetuin-A is present in stenotic aortic valves but not in normal control valves. This may seem paradoxical given the anti-calcific properties of Fetuin-A, however, these data are in accordance with previous reports that have localized fetuin-A in calcified areas of atherosclerotic arteries $(12,25)$. 
Moreover, increased tissue levels and lowered serum levels of other anti-calcific factors have been demonstrated in vascular calcification (35). According to our results, fetuin-A staining was strong at the borders and within the calcification foci, which is likely due to the high affinity of Fetuin-A to hydroxyapatite as observed in the skeleton (26). On a cellular level, fetuin-A is involved in the removal of intracellular precipitates as determined by its presence in matrix vesicles $(8,12)$. Cardiovascular calcification is thought to be initiated by release of matrix vesicle-like structures, and apoptotic bodies may act as a core for basic calcium phosphate nucleation (27). Fetuin-A is known to shield VSMC in numerous ways from deleterious calcium overload, to augment phagocytosis of apoptotic cells and to blunt the related oxidative burst, thus reducing the development of nucleating sites for calcification $(9,10,28-31)$. Since apoptosis is an essential early event during the pathogenesis of cardiovascular calcification, these properties of Fetuin-A might contribute to a potential protective effect against valvular calcification (27). Thus, the presence of Fetuin-A in stenotic but not in normal valve tissue could represent an adaptive process as described in arterial calcification (35).

Whereas cardiovascular risk factors, albeit closely related to atherosclerosis, did not seem to be associated with AS (32) our present observations support the concept that disturbances of calcium homeostasis may contribute to the pathogenesis of AS $(32,33)$. While earlier reports have focused on the effects of fetuin-A deficiency during the cardiovascular calcification syndrome in ESRD patients, the present data are the first to report this association in patients with calcific aortic valve stenosis without ESRD. Moreover, the difference was particularly evident in patients with a GFR $\geq 60 \mathrm{ml} / \mathrm{min}$, indicating an effect of the calcium homeostasis independently of renal diseases. We demonstrated that fetuin-A is deposited at sites of calcification in stenotic aortic valves, suggesting not only a systemic, but also a local effect of fetuin-A. Together with recent reports on genetic variants in the vitamin $\mathrm{D}$ receptor product, these data add further evidence to the hypothesis that mechanisms of calcium homeostasis are likely to be involved in the pathogenesis of calcific aortic stenosis, even in the absence of renal dysfunction (34). Additional studies are needed to elucidate whether this could be a target of therapeutic intervention.

\section{Acknowledgements}

The authors thank Ms. Claudia Liebetrau for her excellent laboratory assistance.

\section{References}

1. Coussens LM, Raymond WW, Bergers G, et al: Inflammatory mast cells up-regulate angiogenesis during squamous epithelial carcinogenesis. Genes Dev 13: 1382-1397, 1999.

2. Mohler ER III, Adam LP, McClelland P, Graham L and Hathaway DR: Detection of osteopontin in calcified human aortic valves. Arterioscler Thromb Vasc Biol 17: 547-552, 1997.

3. Kaden JJ, Bickelhaupt S, Grobholz R, et al: Expression of bone sialoprotein and bone morphogenetic protein-2 in calcific aortic stenosis. J Heart Valve Dis 13: 560-566, 2004.

4. Ketteler M, Wanner C, Metzger T, et al: Deficiencies of calciumregulatory proteins in dialysis patients: a novel concept of cardiovascular calcification in uremia. Kidney Int Suppl: S84-S87, 2003.
5. Schafer C, Heiss A, Schwarz A, et al: The serum protein alpha 2-Heremans-Schmid glycoprotein/fetuin-A is a systemically acting inhibitor of ectopic calcification. J Clin Invest 112: 357-366, 2003.

6. Heiss A, DuChesne A, Denecke B, et al: Structural basis of calcification inhibition by alpha 2-HS glycoprotein/fetuin-A. Formation of colloidal calciprotein particles. J Biol Chem 278: 13333-13341, 2003.

7. Price PA, Thomas GR, Pardini AW, Figueira WF, Caputo JM and Williamson MK: Discovery of a high molecular weight complex of calcium, phosphate, fetuin, and matrix gammacarboxyglutamic acid protein in the serum of etidronate-treated rats. J Biol Chem 277: 3926-3934, 2002.

8. Reynolds JL, Joannides AJ, Skepper JN, et al: Human vascular smooth muscle cells undergo vesicle-mediated calcification in response to changes in extracellular calcium and phosphate concentrations: a potential mechanism for accelerated vascular calcification in ESRD. J Am Soc Nephrol 15: 2857-2867, 2004.

9. Szweras M, Liu D, Partridge EA, et al: alpha 2-HS glycoprotein/ fetuin, a transforming growth factor-beta/bone morphogenetic protein antagonist, regulates postnatal bone growth and remodeling. J Biol Chem 277: 19991-19997, 2002.

10. Jersmann HP, Dransfield I and Hart SP: Fetuin/alpha2-HS glycoprotein enhances phagocytosis of apoptotic cells and macropinocytosis by human macrophages. Clin Sci 105: 273-278, 2003.

11. Floege $\mathrm{J}$ and Ketteler M: Vascular calcification in patients with end-stage renal disease. Nephrol Dial Transplant 19 (suppl 5): V59-V66, 2004.

12. Moe SM, Reslerova M, Ketteler M, et al: Role of calcification inhibitors in the pathogenesis of vascular calcification in chronic kidney disease (CKD). Kidney Int 67: 2295-2304, 2005.

13. Kaden JJ, Dempfle CE, Grobholz R, et al: Interleukin-1 beta promotes matrix metalloproteinase expression and cell proliferation in calcific aortic valve stenosis. Atherosclerosis 170: 205-211, 2003.

14. Stenvinkel P, Wang K, Qureshi AR, et al: Low fetuin-A levels are associated with cardiovascular death: Impact of variations in the gene encoding fetuin. Kidney Int 67: 2383-2392, 2005.

15. Ketteler M, Bongartz P, Westenfeld R, et al: Association of low fetuin-A (AHSG) concentrations in serum with cardiovascular mortality in patients on dialysis: a cross-sectional study. Lancet 361: 827-833, 2003.

16. Mathews ST, Singh GP, Ranalletta M, et al: Improved insulin sensitivity and resistance to weight gain in mice null for the Ahsg gene. Diabetes 51: 2450-2458, 2002.

17. Binkert C, Demetriou M, Sukhu B, Szweras M, Tenenbaum HC and Dennis JW: Regulation of osteogenesis by fetuin. J Biol Chem 274: 28514-28520, 1999.

18. Demetriou M, Binkert C, Sukhu B, Tenenbaum HC and Dennis JW: Fetuin/alpha2-HS glycoprotein is a transforming growth factor-beta type II receptor mimic and cytokine antagonist. J Biol Chem 271: 12755-12761, 1996.

19. Mohler ER III, Chawla MK, Chang AW, et al: Identification and characterization of calcifying valve cells from human and canine aortic valves. J Heart Valve Dis 8: 254-260, 1999.

20. Jian B, Narula N, Li QY, Mohler ER III and Levy RJ: Progression of aortic valve stenosis: TGF-beta1 is present in calcified aortic valve cusps and promotes aortic valve interstitial cell calcification via apoptosis. Ann Thorac Surg 75: 457-465, 2003.

21. Kaden JJ, Kilic R, Sarikoc A, et al: Tumor necrosis factor alpha promotes an osteoblast-like phenotype in human aortic valve myofibroblasts: a potential regulatory mechanism of valvular calcification. Int J Mol Med 16: 869-872, 2005.

22. Kaden JJ, Dempfle CE, Grobholz R, et al: Inflammatory regulation of extracellular matrix remodeling in calcific aortic valve stenosis. Cardiovasc Pathol 14: 80-87, 2005.

23. Shioi A, Katagi M, Okuno Y, et al: Induction of bone-type alkaline phosphatase in human vascular smooth muscle cells: roles of tumor necrosis factor-alpha and oncostatin $\mathrm{M}$ derived from macrophages. Circ Res 91: 9-16, 2002.

24. Tintut Y, Patel J, Parhami F and Demer LL: Tumor necrosis factor-alpha promotes in vitro calcification of vascular cells via the cAMP pathway. Circulation 102: 2636-2642, 2000.

25. Kazama JJ, Gejyo F and Ei I: The immunohistochemical localization of alpha2-Heremans-Schmid glycoprotein/fetuin-A (AHSG). Nephrol Dial Transplant 20: 851-852, 2005.

26. Schinke T, Amendt C, Trindl A, Poschke O, Muller-Esterl W and Jahnen-Dechent W: The serum protein alpha2-HS glycoprotein/fetuin inhibits apatite formation in vitro and in mineralizing calvaria cells. A possible role in mineralization and calcium homeostasis. J Biol Chem 271: 20789-20796, 1996. 
27. Proudfoot D, Skepper JN, Hegyi L, Bennett MR, Shanahan CM and Weissberg PL: Apoptosis regulates human vascular calcification in vitro: evidence for initiation of vascular calcification by apoptotic bodies. Circ Res 87: 1055-1062, 2000.

28. Reynolds JL, Skepper JN, McNair R, et al: Multifunctional roles for serum protein fetuin-a in inhibition of human vascular smooth muscle cell calcification. J Am Soc Nephrol 16: 2920-2930, 2005.

29. Hart SP, Jackson C, Kremmel LM, et al: Specific binding of an antigen-antibody complex to apoptotic human neutrophils. Am J Pathol 162: 1011-1018, 2003.

30. Lewis JG and Andre CM: Enhancement of human monocyte phagocytic function by alpha $2 \mathrm{HS}$ glycoprotein. Immunology 42: 481-487, 1981

31. Terkeltaub RA, Santoro DA, Mandel G and Mandel N: Serum and plasma inhibit neutrophil stimulation by hydroxyapatite crystals. Evidence that serum alpha $2-\mathrm{HS}$ glycoprotein is a potent and specific crystal-bound inhibitor. Arthritis Rheum 31: 1081-1089, 1988 .
32. Ortlepp JR, Schmitz F, Bozoglu T, Hanrath P and Hoffmann R: Cardiovascular risk factors in patients with aortic stenosis predict prevalence of coronary artery disease, but not the prevalence of aortic stenosis. An angiographic pair matched case-control study. Heart 89: 1019-1022, 2003.

33. Ortlepp JR, Pillich M, Schmitz F, Mevissen V, Koos R, Weiss S, Stork L, Dronskowski R, Langebartels G, Autschbach R, Brandenburg V, Woodruff S, Kaden JJ and Hoffmann R: Lower serum calcium levels are associated with greater calcium hydroxyapatite deposition in native aortic valves of male patients with severe calcific aortic stenosis. J Heart Valve Dis 15: 502-508, 2006.

34. Ortlepp JR, Hoffmann R, Ohme F, Lauscher J, Bleckmann F and Hanrath $\mathrm{P}$ : The vitamin $\mathrm{D}$ receptor genotype predisposes to the development of calcific aortic valve stenosis. Heart 85: 635-638, 2001.

35. Vattikuti R and Towler DA: Osteogenic regulation of vascular calcification: an early perspective. Am J Physiol Endocrinol Metab 286: E686-E696, 2004. 